\title{
Breaking Reality: Exploring Pervasive Cheating in Foursquare
}

\author{
René Glas \\ Assistant Professor New Media and Digital Culture \\ Media and Culture Studies \\ Faculty of Humanities \\ Utrecht University \\ Muntstraat 2a \\ 3512 EV Utrecht \\ The Netherlands \\ r.glas@uu.nl
}

\begin{abstract}
This paper explores the notion of cheating in location-based mobile applications. Using the popular smartphone app Foursquare as main case study, I address the question if and how devious practices impact the boundaries between play and reality as a negotiated space of interaction. After establishing Foursquare as a prime example of the gamification phenomenon and pervasive gaming, both of which require us to rethink notions of game and play, I will argue that cheating in location-based mobile applications challenges not just the boundaries of play, but also of playful identity.
\end{abstract}

\section{KEYWORDS}

Cheating, Gamification, pervasive games, ludification of culture, location-based games, playful identity.

\section{INTRODUCTION}

"ळ. This ain't Seaworld, this is as real as it gets / I'm on a boat, MF'er, don't you ever forget! J"" (I'm on a Boat!, The Lonely Island, 2009)

These song lyric lines accompanied a badge I earned in February 2010 while using Foursquare on my mobile phone. This location-based social network service, created by Dennis Crowley and Naveen Selvadurai and launched in 2009, offers its users to check-in at real-world venues, earning rewards (like badges) in the process. The badge I was rewarded, appropriately called "I'm on a Boat!", is the reward from the first time you actually check in on a boat in real life.

The problem, however, is that I never actually was on a boat. I checked in at Amsterdam Central Station to take the train to work. Foursquare's virtual venues are supposed to be linked directly to real venues, but Central Station was virtually changed into something else. Amsterdam Central Station "ain't Seaworld", to use The Lonely Island's lyrics, but for Foursquare users, it suddenly was also no

Proceedings of DiGRA 2011 Conference: Think Design Play.

(C) 2011 Authors \& Digital Games Research Association DiGRA. Personal and educational classroom use of this paper is allowed, commercial use requires specific permission from the author 
longer "as real as it gets". And in case I would "ever forget", Foursquare had automatically posted the fact that I earned the badge on my Facebook wall, triggering friends to not only question my real location but also my sincerity: "Have you started cheating?"

After a short investigation, I found out what happened. As a service depending on user participation, Foursquare invites its users to not only add new venues to the database, but also to describe what these venues are, or what you can find there, through a system of tags. Many different tags are possible, but only some of them are linked to badge rewards. The person responsible for the "I'm on a Boat!" badge had to know; he or she apparently added the tag "boat" to the station. By doing so, this person not only cheated the system, but included me - and everyone else checking in before the tag was removed - in his or her devious act.

This exploratory paper deals with the notion of cheating in the location-based mobile social networking application Foursquare. It addresses the question if and how devious practices like the one described above impact the boundaries between play and reality as a negotiated space of interaction. Having actively participated in Foursquare, and observed its developments for over a year, the application will act as my main case study. Foursquare, with its millions of users, is furthermore exemplary for what has become known as gamification, a phenomenon which stretches the notion of what constitutes a game. To investigate the conceptual boundaries of play, I will start by elucidating what the gamification phenomenon entails. I will then move on to frame Foursquare as a pervasive game and, subsequently, cheating in Foursquare as pervasive cheating. The focus on the pervasive nature of Foursquare is central to my argument that cheating in these types of location-based mobile media results in shifts in control and agency over play, as well as the playful identity, of the various parties involved.

\section{THE MATTER OF GAMIFICATION}

The term "gamification" is a true buzzword. While we lack any clear definition of the term, it generally describes the implementation of game-like characteristics in other media. As game designer Jesse Schell put it during one of the many gamification conference panels, gamification is "taking things that aren't games and trying to make them feel more like games" (quoted in Graft 2011). The goal is to make media more engaging by making them feel playful in nature - to "gamify" them - through various reward systems.

Gamification, however, it is in danger of following the path of "interactivity" which, as game scholar Espen Aarseth has noted, became a form of industry rhetoric implying that "the role of the consumer had (or would very soon) change for the better" (1997, p. 48). The way gamification is put forward as a revolutionary force in media use sometimes is similar in terms of rhetoric. Take, for instance, this quote about Foursquare from game designer Jane McGonigal's prominent book Reality is Broken:

[...] what makes a Foursquare social life better than your regular social life is the simple fact that to do well in Foursquare, you have to enjoy 
yourself more. You have to frequent your favorite places more often, try things you've never tried before, go places you've never been, and meet up more often with friends whom you might not ordinarily make time to see in person. In other words, it's not a game that rewards you for what you're already doing. It's a game that rewards you for doing new things, and making a better effort to be social. (McGonigal 2011, p. 166).

While McGonigal calls Foursquare a "good game” (2011, p. 167), gamification's detractors would argue that an app like Foursquare is hardly a game at all. It is a borderline-case at best when viewed through standard game definitions (cf. Salen and Zimmerman 2004; Juul 2005), and some argue that apps like Foursquare consist mostly (or only) out of feedback systems, not any game mechanics (Deterding 2010; Bogost 2011). Feedback systems, like points or badges, are seldom part of gameplay; they usually communicate the results of gameplay. As game designer and critic Margaret Robertson argues: "what we're currently terming gamification is in fact the process of taking the thing that is least essential to games and representing it as the core of the experience" (Robertson 2010 , emphasis in original). She proposes the alternative term "pointsification" to describe the phenomenon, adding that while the implementation of game-like reward systems in media are not bad per se, it has the potential to strip out the sense of agency and competence so important for gameplay (ibid.). It should also be said that the team behind Foursquare does not consider it to be a game - on the official website it is referred to as a location-based mobile platform. That the company sometimes has trouble addressing the exact nature of this platform, becomes clear in a statement by Foursquare's head of product, Alex Rainert. In an interview, he stated that they "don't consider Foursquare a game", adding that they do "recognize the value of using game mechanics to change behaviors" (van Buskirk 2011), seemingly disagreeing with both supporters (it is not a game) and critics (it does have game mechanics) of gamification.

While the discussion above is certainly interesting, it is not my goal in this paper to untangle the different, sometimes conflicting views on gamification, or argue for or against the phenomenon. Rather, I want to explore play practices that emerge from the increased implementation of game-like characteristics in location-based mobile media. What has been called gamification can be seen as part of a larger process of "ludification" of culture which can be traced back to the 1960s (e.g. Stenros et al 2009, Frissen et al forthcoming). With playfulness increasingly pervading mainstream culture, the gamification phenomenon only adds to the articulation of the playful dimensions of our individual and cultural identity. ${ }^{\text {i }}$

Critics might lament gamification's exchange of gameplay for feedback-systems as the core experience of play, for some players, playing the feedback system however is the core of the experience. For these players, the "new things" they undertake through Foursquare might not involve getting out more or being more social, as McGonigal attests in her work. Instead, these new things could involve finding out new ways to actually not leave the house at all, or being rather anti- 
social, while still receiving the same rewards as those who play "by the rules". Such players, who do not play by but rather against the rules, are usually referred to as cheaters.

According to the Foursquare FAQ, cheating is not a "widespread" phenomenon within the service (Foursquare 2010). Many instances of cheating are subtle and often indirect, creating at the most annoyance with other users. I will, however, point out at that instances of cheating do bring with it new considerations for thinking about the creation of playful identities, as well as how cheating practices impact the relationship between play and non-play (i.e. regular use) in locationbased mobile applications like Foursquare. If we want to explore the notion of cheating in these media, we need to first acknowledge that cheating, both as a practice and as a term describing such practices, is rather hard to define. To understand the volatile nature of cheating, one should first look at the boundaries of play.

\section{FRAMING THE FOURSQUARE EXPERIENCE}

Cheating describes a host of deviant, devious, anti-social and/or unsportsmanlike practices which break the metaphorical "magic circle" which separates the activity of play from the outside world. This magic circle therefore supposedly defines the boundaries of play. The concept is that breaking the magic circle, which some forms of cheating does, results in play being suspended momentarily or indefinitely by the players and/or referee. The term originates from Johan Huizinga's Homo Ludens (1955) and has been subject of much discussion within game studies since the early 2000s.

The consensus seems to be that the magic circle, if such a boundary would exists, never really excludes the outside world. It is framed as an imperfect separation which players negotiate and uphold (Juul 2008); a ritualistic contract based on implicit agreements, a form of social etiquette or protocol (Montola 2009; Glas 2010); or as non-existent, as ordinary life always pervades play (Pargman and Jakobsson 2008; Consalvo 2009). Goffman's discussion of frame analysis, as embraced by sociologist Gary Alan Fine in his classic ethnographic study of tabletop fantasy gaming (Goffman 1974; Fine 1983), has become a prevalent alternative for the magic circle concept. Rather than dealing with a somewhat formalist notion of boundaries between the play world and the real world, frame analysis looks at different levels of engrossment players experience when engaging a game. Players organize these experiences through frames of meaning. While the types of frame which can form during play are endless, Fine focuses on three main frames: the primary frame of the real world grounding all activities; the game context with its rules and structures; and the fictional world presented within the game in which players are present as characters (1983, pp. 183-86).

The concept of frames is helpful when dealing with gamified media like Foursquare, as it leaves more room for games which, like the role-playing games Fine studied, deviate from classic game models. As a location-based social 
network application, Foursquare can be considered a pervasive game, a type of game with one or more salient features which expand the spatial, temporal, or social boundaries of play (Montola 2009, p. 12). Foursquare exhibits all three forms of boundary expansion. First, it uses the real world as its playground and as such does not feature a fictional game world in which players create characters. While the explicit link with the real world does not prevent players from creating fictional characters ii, in theory, players "play" with themselves. Second, while there are weekly rankings of top users, the game is persistent rather than divided into separate play sessions. Third, Foursquare features a large amount of nonparticipants among its users, expanding the game beyond the core players.

The argument that Foursquare includes nonparticipants among its users might need some elaboration. Playing Foursquare does not seem to involve any bystanders, at least not in the way many pervasive games use them as audience, challenge or obstacle (Montola et al 2009). There are, however, nonparticipants active within Foursquare itself. It might be considered a pervasive game due to its gamified nature, for many users, it is mainly a location-based social network application. As media scholars Valerie Frissen, Jos de Mul and Joost Raessens point out in their work on playful identity, "a playful affordance is [...] 'virtual' (in the sense of a potentiality) until it is actualized by the playful attitude of the user and experienced as such. (forthcoming)". Not all Foursquare users engage with the service with such an attitude, and for them, it might never feel like a game. Due to the fact that these users are aware of the playful affordance of Foursquare (they too receive points and badges when checking in), they are not "unaware participants" (Montola 2009, p. 16) but rather aware nonparticipants in play.

While the line between being a player and user is thin (even non-players enjoy earning the occasional badge or mayorship), the difference matters for the overall experience of a gamified medium. From a frame analysis perspective, players and users approach Foursquare from a noticeably different frame. As Fine points out, every frame has meanings associated with it, and "these meanings are not necessarily shared with figures (persons, players, characters) operating in other frames" (1983, p. 187). The regular user's experience of Foursquare, for the most part, remains in the primary frame of the real world, which makes them less sensitive for issues which matter for players who are engaged in the game from a ludic frame.

\section{PERVASIVE CHEATING}

The dual experience of Foursquare as a game and as a location-based social app manifested through the presence or absence of a playful attitude - is usually not thought of as problematic by either players or other users. Players, for instance, benefit from other users' involvement in adding and editing locations to the game, expanding their playground. Conversely, users can see their experience enhanced by players who never miss a check-in anywhere they go, making Foursquare feel alive as a social service. The exposure to each other's attitude and practices 
mostly remains indirect. Players who cheat, however, do not only potentially break the metaphorical magic circle of other players, they also directly expose non-players to their antics, potentially breaking or at least influencing their user experience as well. Montola states that "pervasive games can take the pleasure of the game to ordinary life" $(2009$, p. 21$)$. Cheating in pervasive games, or pervasive cheating, can, as I will show below, pull ordinary life into a game whether non-players want to or not.

As an application heavily dependent on user-generated content and honest behavior when it comes to check-ins, Foursquare offers ample opportunity for cheating practices. As a result, cheating practices vary greatly in form and (perceived) severity. Cheating practices are not limited to breaking the boundaries of play which result from the social negotiation processes discussed above. The socially negotiated rules could be called "soft rules". In digital games, however, there are also "hard rules", which are presented through the actual game code (Consalvo 2007, p. 87). Additionally, everyone using a service like Foursquare agrees to obey certain contractual rules put forward in Terms of Service documents. Cheating in digital games therefore is sociotechnical in nature, with the rules and boundaries of play both set and contested on the levels of play, game design, game contracts and game culture (Kücklich 2008; De Paoli and Kerr 2009; Glas 2010). With pervasive cheating, the act and effect of cheating is further complicated due to the different frames of engrossment through which players and users approach Foursquare. While this paper will forego an effort to categorize cheating practices, I will explore different forms of cheating to show how they affect the various parties involved in creating, playing and using Foursquare, as well as how these parties all have different stakes in pursuing and contesting pervasive cheating.

\section{THE STAKES OF FOURSQUARE}

All parties with certain interests in a game can be considered stakeholders. In the case of Foursquare, these parties include the aforementioned players and users, but also its makers and other companies and businesses associated with the game. Whether their interests are commercial or affective in nature, all stakeholders "strive to achieve what they think is in the game's or their own best interest" (Glas 2010, p. 41). Cheaters are no exception: while their practices might be deemed deviant or even devious, many of them see their activities as highly pleasurable. They too can be seen as stakeholders. In the following sections, I will seek to describe how Foursquare's stakeholders are affected and subsequently deal with cheating differently, exposing various negotiations between these stakeholders about the rules of play which provide valuable insight in the ways cheating influences the pervasive nature of the play in gamified media.

\section{The players}

According to Salen and Zimmerman, there is a hypothetical "standard" and honest game player who plays a game as it was designed to be played. This player type forms the "test case against which all other types of players are contrasted" as it is 
the most "law-abiding citizen" when it comes to following the (hard) rules (2004, pp. 268-269). The other types they mention (the dedicated player, the unsportsmanlike player, the cheat and the spoil-sport) all deviate in various ways from the rules of play, by finding ways around them, breaking them or ignoring them altogether (ibid.). The standard player, however, is an idealized player, at least from the viewpoint of most game designers. While Salen and Zimmerman rightfully point out that such an ideal player might not exist, the idea itself provides a "backdrop against which less rule-governed styles of play can be understood" (2004, p. 269).

And indeed, while most Foursquare players would probably consider themselves standard players, many do bend the rules. The idea behind checking-in at venues, for instance, is that you only do so when you are actually there. Many players, however, check in beforehand (to show friends they are on their way) and/or retroactively (in case they forgot a check-in). One reason is that the app tracks and keeps all your check-in data, making it available on the website for yourself and, if desired, others. Many players (and regular users) like this list to be as complete as possible. While not complying with the basic check-in rules, these practices are generally considered acceptable behavior, showing that what defines a standard player does not just rely on the way a game is designed, but also by the rules created and negotiated socially. In a blog post on cheating practices, the Foursquare design team shows it is well aware of these socially accepted rules: "we're fine with pre-check-ins and post-check-ins [...] (Trust us, we do it too to fill out our history pages!)" (Team Foursquare 2010).

While check-in etiquette might be lenient toward pre- and post-check-in practices, for standard players, honesty about checking-in is nevertheless seen as key to the Foursquare play experience. According to disgruntled players, the first year after Foursquare's launch in March 2009 saw rampant dishonest check-ins. During this period, it was easy to check-in at any location from anywhere. This situation forced Foursquare to implement "cheater code" (discussed below), but also triggered player to vent their dissatisfaction through social media like Twitter and blogs.

The players' ire was particularly provoked by people using dishonest check-ins to become mayor of venues. Becoming mayor through standard play requires consecutive visits to places, and only the person who has visited such place most is crowned mayor. Places like train stations and coffeehouses are therefore hotspots for Foursquare players trying to oust each other as mayor. In terms of time investment, being a mayor of such a hotspot has high value for players and one can imagine the frustration if someone who has never been there suddenly grabs the mayorship. ${ }^{\text {iii }}$ When the stakes are high for players abiding the rules of play in gamified media, cheating can feel just as destructive as in classic games. 


\section{The cheaters}

Why players cheat or in other ways deviate from the rules (social and/or coded) is difficult to address. As game scholar Mia Consalvo points out after having conducted countless interviews on why players cheat, "perhaps the only constant is the lack of a constant factor" (2007, p. 94). In the case of the "I'm on a Boat!" badge, the person responsible might just have wanted the badge without going to the trouble of actually going to a boat. Maybe adding the \#boat tag was a joke, as right behind the station area is enough water with enough boats on it. Maybe he or she wanted to annoy (or please) other Foursquare users by forcing the badge upon them. Maybe he or she just wanted to show how easy it is to trick the system.

While the reasons behind deviant behavior might differ, an overarching theme in the way players generally talk about cheating in games is that it provides an unfair advantage over those who play by the rules (Consalvo 2007, p. 87). In a game like Foursquare, which hardly has any quantifiable outcomes which could be deemed a winning scenario, this advantage might sound superfluous. With the exception of deviously achieving a mayorship, which might directly affect players striving for this position the standard way, in most cases cheating in Foursquare only affects other players indirectly, lessening the impact of cheating considerably. This suggests cheating in a game like Foursquare functions mostly to annoy other players. Some cheaters have, however, invested larger stakes in the way the play and cheat - the game.

An interesting case to illustrate this point is the phenomenon of Indonesian cheaters. In 2010, many player complaints were heard about this group. These users, whose online profile made it clear they were in fact located in Indonesia, managed to amass almost all badges with thousands of check-ins all over the world. The badges include those tied to very specific locations and/or very specific moments in time. Examples are a badge for having voted on US Mid-term election day, having participated in political comedian Stephen Colbert's "March to Keep Fear Alive" event in Washington DC, or a Banksy Badge which could only be achieved by checking in at select movie theatres playing the Banksy documentary Exit Through the Gift Shop and, while being there, mentioning Banksy in a "shoutout" (one of the ways Foursquare allows you to alert others of your presence). To achieve their large amount of badges and other rewards they managed to check-in from one place to another (including locations in different countries) faster than realistically possible, a deviant practice called "jumping". Many of these Indonesian cheaters were (and still are at the time of writing early 2011) to be found in the top Foursquare user lists.

According to one Indonesian blogger, this trend among Indonesian Foursquare users can be seen as a continuation of their use of social networks sites as a form of popularity contests, where getting as many friends in their network as possible, through whatever means possible and regardless of the fact if they actually know these people ("mia1984" 2010). In her eyes - and those of many other players these users just don't understand how services like Facebook and Foursquare 
work (i.e. what the rules of play are). However, as cultural anthropologist Michiel de Lange points out in his study of mobile media practices in Indonesia, cultural context is important. "Being able to play with, and subvert pre-programmed rules is considered a valuable asset" in Indonesia due to people having lived under the strict rules of Suharto's regime (2010, p. 193). It is not only seen as fun but as a source of prestige among peers. In other words, for these cheaters, the stakes are as such that they consider their behavior not as deviant but as status-enhancing.

\section{Other users}

As said, the distinction between players and other users, or aware nonparticipants, of Foursquare can be difficult the make. When users are the direct or indirect victim of cheating practices, one could argue, however, that the effect is different from players. Cheating for players means that the metaphorical magic circle of play becomes unstable, which transports them back from the play world to the real world. To use Goffmanian terms (1974), the game is temporally downkeyed from the ludic frame to the primary frame. For a user normally not really concerned with the ludic frame, cheating practices can cause a reverse frame switch, where the game is not downkeyed, but instead reality is upkeyed to a ludic level.

To explain this process of frame switching, I can use the "I'm on a Boat!" anecdote as an example. The fact that Amsterdam Central Station was turned into a boat within Foursquare's venue database confronts users with the ludic frame, shattering the service's supposed link to the real world. Furthermore, the unfair advantage gained by the cheater to get the badge was distributed to both players and users without their consent, making them involuntary and potentially unwilling "accomplices". While I consider myself someone who engaged with Foursquare with a playful attitude - engaging it from a ludic frame - many nonplayers were also affected by the devious action taking place. When they suddenly got the badge that day during their routine check-in, they were turned into cheaters, an identity which is largely linked to the ludic frame of the game rather than the primary frame of the real world.

Cheaters therefore do not just focus non-players' attention on various deviant uses of Foursquare, but can actually pull aware nonparticipants into reluctant (or willing) participation in play. As frames are shifted as a result of cheating practices, we could therefore say that while cheating may break a game for players, it can simultaneously break reality for all others.

While the argument can be made that a playful attitude is always voluntary and can therefore not be forced upon a user by a cheater, the same cannot be said about his or her playful identity. Even when people using Foursquare consider themselves non-players, their user profile still shows the points, badges and mayorships they have earned by using the service. Similar as to how social network profiles function as a way to write oneself (virtual) identity into being (boyd 2007, pp. 13-15), in an increasingly ludic culture profiles like Foursquare's attribute to what can be considered playing ourselves into being. If cheaters mess 
with these profiles, identity construction and/or proliferation of non-player user can be at stake.

\section{The designers}

The design team behind Foursquare is well aware of cheating practices and the grievance it can cause to both players and non-players. They have implemented barriers against practices they deem cheating. On the level of game contract, for instance, they warn users against taking any action, or contribute any content which "you know is false, misleading, untruthful or inaccurate" (from the Terms of Use, Foursquare 2011). These game contracts, which all users agree to when they create their account, allow the design team to block or even cancel accounts. On a technical level there is the aforementioned "cheater code" to prevent location cheating. While Foursquare's design team keep details about their anti-cheating techniques deliberately sketchy, an investigative study shows that it involves using a phone's GPS for location verification, monitoring check-in frequency at single venues, distance between different check-in venues, and rapid-fire checkins in multiple venues in one location (He et al 2011).

While the measures mentioned above sound tough, checking-in while not actually physically being at a venue remains possible. The catch is that the potential to unlock rewards (mayorships, points, badges) is blocked during false check-ins. Technical loopholes to reach these rewards still exist, as shown by the Indonesian cheaters who mostly check in through mobile web browsers (an option developed as an alternative for users without GPS-enabled phones). While checking in through mobile web browsers does allow users to earn badges and many of Foursquare's other social networking functionalities, it does not count check-ins for mayorships. This design prevents users without access to modern smartphone hardware and data plans from becoming mayor but, at the same time, does not stop those willing to cheat to exploit the potential to earn badges deviously. ${ }^{\text {iv }}$

Foursquare's design team makes no secret of balancing issues like these. Commenting on a well-known cheater's blog post, the company's co-founder Dennis Crowley asks:

"what's more valuable - a system in which everyone can play \& participate? Or a system that places emphasis on the validity of each check-in/post at the expense of all-inclusiveness? I think the thing that makes foursquare so interesting - and yet so difficult - is that it wants to be both things at the same time. And if you survey users, just as many use it for finding their friends as they do for trying to get points / badges / mayorships" (Crowley, in a comment on Krazydad 2010).

What these remarks show is that Foursquare is designed to appease both players and users existing on different frames of engrossment. Cheaters, on the other hand, constantly raise the stakes for the designers, prompting them to act against them to keep the playful spirit of Foursquare alive while preventing other users to leave in frustration due to overly strict check-in system. Keeping both players and 
other users on board is important as the service's business model depends on it, which brings us to the final stakeholder group discussed in this paper.

\section{Businesses}

As Foursquare is a free-to-use service for users, its business model depends on other means of income. Primary sources of income are marketing partnerships, with brands using the service to reach the social media crowd. Foursquare reward system is comparable to the loyalty programs like airline's frequent flyer systems, rewarding repeat customers in a similar fashion (Bogost 2010). Interested parties can tap into this loyalty by offering promotional, brand-unique badges. For venue owners, a free set of tools is available to setup Specials for regular customers or mayors. These forms of in-game marketing, in which both Foursquare and participating businesses do not have affective but commercial stakes, can be derailed by cheating practices.

Specials are especially sensitive to exploitation. Promoting a Special, like free drinks in a bar for the mayor, invites potentially dishonest check-in behavior. This in turn might put off honest players - potential customers for a business. To protect their customers against situations like this, in late 2010, Foursquare began offering businesses the possibility to oust mayors from their venues if they have reason to believe the mayorship is not gained through legitimate means. ${ }^{\mathrm{v}}$ Understandable from a commercial perspective, decisions like these make businesses, rather than game makers or players, into arbiters of the rules of play.

While the experience of players and non-player users, as well as the content they generate, matters greatly to the design team, we should not underestimate external business partners, whether they are big brands buying their own badges or small companies using the free Specials tool. They are increasingly becoming key stakeholders, forming a source of (potential) revenue and fuelling growth of gamified media like Foursquare, but also acting as participants in the realm of play. If and how these commercial parties use (and potentially misuse) their agency over the rules of play, is beyond the scope of this paper, but unquestionably shines new light on how the boundaries of play are negotiated in gamified media and culture.

\section{CONCLUSION}

In their discussion of pervasive games in media culture, game researchers Jaakko Stenros, Markus Montola, and Frans Mäyrä have pointed out that a clear distinction between serious and playful mindsets and contexts is not sufficient to cover all pervasive play forms. They argue that it "omits the constantly growing phenomena of fabrication and pretense, which exist in the gray borders of playfulness" (2009, p. 271). Both fabrication and pretense result in situations where one party is oblivious of a playful situation while the other is not. This paper has been an effort to address another such grey area of pervasive games, cheating, where all parties are aware of the presence of a playful situation, but deviant practices challenge the boundaries between play and ordinary life. To be 
able to do so, I first engaged in a discussion about the status of these boundaries in gamified media and pervasive games, concluding that cheating adds further complexity to the already blurred distinction between play and non-play inherent to these forms of games. By exploring various forms of cheating as well as how different stakeholders influence and are influenced by these practices, I have shown that cheating can be much more than just a nuisance. Similarly to fabrication and pretense, where an "asymmetry in information also creates an asymmetry in power and control" (Stenros et al 2009, p. 273), cheaters can create situations where other stakeholder's agency over gamified media like Foursquare - and, as a consequence, their own playful identity - is at stake.

Game scholar Julian Kücklich reminds us that the study of cheats "foregrounds the fact that games are embedded into a larger social and cultural context with undeniable links to the world we inhabit" (2008, p. 69). With the phenomenon of gamification on the rise in our culture, we will most certainly see an increase in the amount and variety of pervasive cheating practices. As such, further research is needed to explore the concept of cheating in relation to the increasingly prominent role of playful identity in our culture.

There are, however, other venues for research which result from the notion of pervasive cheating. Kücklich for instance points out that cheating in massively multi-player online role-playing games (or MMORPGs) is of special interest:

as these [games] are novel participatory media forms that are infused with cultural codes from the real world such as the flow of currency and commodities. Insofar as the characters themselves become a commodity in MMORPGs, cheats that address this commodification can be said to possess critical potential (Kücklich 2008, p. 69).

Like MMORPGs, gamified media like Foursquare are novel participatory media forms too, and here cheating has critical potentials as well. Take, for instance, Bogost's argument that gamification, or "exploitationware" as he suggests to call it, perverts the traditional two-way relationship between institutions and customers. In his view, "organizations ask for loyalty, but they reciprocate that loyalty with shams, counterfeit incentives that neither provide value nor require investment" (2011, p. 4). From this perspective, we should explore if and how pervasive cheating practices which highlight the futility of gamification's reward systems have the potential to confront players with this asymmetrical relationship.

The link between cheating and critique is not limited, however, to exposing the business models behind the gamification phenomenon. Players themselves find other creative uses for manipulating the rules of play. I have, for instance, come across a Foursquare venue which, translated from Dutch, was named "Hangout for idlers, potential criminals and people who've lost their ways" and was tagged with terms like \#freeloaders, \#homeless and \#dangerous. Additionally, someone used Foursquare's "tips" option (usually reserved for positive feedback about a 
venue) pointing out how the local government had failed to stop impoverishment of the building in question - as it turned out, an old high school turned squat. Entries like these suggest that bending the rules of a playful platform like Foursquare can be used for political activism.

While we could argue if actions like these can still be considered a form of cheating, the link between pervasive cheating and critique is nevertheless intriguing. It again shows that, as a practice pervading the spatial, temporal, and social boundaries of play, pervasive cheating has the potential to affect the real world in unexpected ways.

\section{ACKNOWLEDGMENTS}

Special thanks to Sybille Lammes for valuable and critical comments on earlier versions of the paper.

\section{ENDNOTES}

${ }^{i}$ Frissen et al. aim to develop a theory of ludic identity construction, which they consider an "update" of Ricœur's theory of narrative identity (forthcoming).

ii Some Foursquare users do create fictional characters, often meant for humorous purposes. One cheater admitted having created, among others, a fake Martha Stewart checking into dollar stores and pawnshops, a fake Tommy Chong who he made mayor of 120 cannabis clinics and a "random nerd" who likes to check in at large Silicon Valley campuses (Krazydad 2010).

iii As Foursquare was one of the first big gamification phenomena early 2010, the frustration about cheating practices during battles for mayorships even entered pop culture. Popular webcomic Player vs Player, for instance, dedicated a story arc to it (Kurtz 2010), and it even spawned an online video series called Foursquare Cops (Tondorf 2010).

iv This situation has furthermore prompted the design team to implement a system in which players suspected of cheating practices are flagged. When deemed guilty, they will have their accounts blocked from earning any rewards.

${ }^{v}$ Additionally, business can assign employees and managers for their venues (in effect preventing these users from collecting rewards) and display check-in codes on screens which players need to type in for validation.

\section{BIBILIOGRAPHY}

Aarseth, Espen J. Cybertext, Perspectives on Ergodic Literature. Baltimore: The Johns Hopkins University Press, 1997.

Bogost, Ian. (2010) "Persuasive Games: Check-Ins Check Out". Gamasutra. Available at http://www.gamasutra.com/view/feature/4269/persuasive_games_ checkins_check_.php (accessed February, 2011).

Bogost, Ian. (2011) "Persuasive Games: Exploitationware". Gamasutra. Available at ttp://www.gamasutra.com/view/feature/6366/persuasive_games_ exploitationware.php (accessed July, 2011). boyd, danah. "Why Youth (Heart) Social Network Sites: The Role of Networked Publics in Teenage Social Life." In: Buckingham, David (ed.). MacArthur 
Foundation Series on Digital Learning - Youth, Identity, and Digital Media Volume. Cambridge: The MIT Press, 2007.

van Buskirk, Eliot. (2011) "Foursquare: the SXSW interview." Wired.com Underwire. Available at http://www.wired.com/underwire/2011/03/foursquarethe-sxsw-interview/ (accessed March, 2011).

Consalvo, Mia. Cheating: Gaining Advantage in Videogames. Cambridge: The MIT Press, 2007.

Consalvo, Mia. "There is no Magic Circle." Games and Culture vol. 4, no. 4 (2009): pp. 408-17.

Crowley, Dennis and Selvadurai, Naveen (2009). Foursquare. Foursquare Labs, Inc.

Deterding, Sebastian. "Pawned. Gamification and its Discontents". Playful 2010. September 24, London, 2010. Available at http://www.slideshare.net/dings/

pawned-gamification-and-its-discontents (accessed March, 2011).

Fine, Gary Alan. Shared Fantasy: Role-Playing Games as Social Worlds. Chicago: The University of Chicago Press, 1983.

Foursquare. (2010) "Foursquare FAQ: How do you prevent people from cheating?" Available at http://support.foursquare.com/entries/195341-how-doyou-prevent-people-from-cheating/ (accessed April, 2011)..

Foursquare. (2011) "Foursquare Labs, Inc. Terms of Use." Available at https://foursquare.com/legal/terms (accessed April, 2011).

Frissen, Valerie, Jos De Mul, and Joost Raessens. "Homo Ludens 2.0: Play, Media, \& Identity." In: Valerie Frissen, Sybille Lammes, Michiel de Lange, Jos de Mul and Joost Raessens (eds.). Homo Ludens 2.0: Play, Media, \& Identity. Amsterdam: Amsterdam University Press, forthcoming.

Glas, René. Games of Stake: Control, Agency and Ownership in World of Warcraft. PhD Diss. Amsterdam: University of Amsterdam, 2010.

Goffman, Erving. Frame Analysis, an Essay on the Organization of Experience. Cambridge: Harvard University Press, 1974.

Graft, Kris. (2011) "GDC 2011: time to ditch the term 'gamification'?" Available at http://gamasutra.com/view/news/33315/GDC_2011_Time_To_Ditch_The_

Term_Gamification.php (accessed April, 2011).

He, Wenbo, Xue Liu, and Mai Ren. Location Cheating: A Security Challenge to Location-Based Social Network Services. arXiv:1102.4135v1, 2011. http://arxiv.org/abs/1102.4135.

Huizinga, Johan. Homo Ludens. Boston: Beacon Press, 1955.

Juul, Jesper. Half-Real, Video Games between Real Rules and Fictional Worlds. Cambridge: The MIT Press, 2005.

Juul, Jesper. "The Magic Circle and the Puzzle Piece". In Grünzel, Stephan, Michael Liebe and Dieter Mersch. Conference Proceedings of The Philosophy of Computer Games. Potsdam: Universität Potsdam, 2008. pp. 56-67.

de Lange, Michiel. "Moving Circles: Mobile Media and Playful Identities." PhD Diss. Rotterdam: Erasmus University, 2010. 
Krazydad. (2010) "Mayor of the North Pole". Available at http://www.krazydad.com/blog/2010/02/mayor-of-the-north-pole/ (accessed February, 2011).

Kücklich, Julian. "Forbidden Pleasures - Cheating in Computer Games". In: Swalwell, Melanie \& Jason Wilson (eds.). The Pleasures of Computer Gaming: Essays on Cultural History, Theory and Aesthetics. Jefferson: McFarland. pp. 5271.

Kurtz, Scott R. (2010) "Hopscotch." PvPonline.com. Available at http://www.pvponline.com/2010/02/03/hopscotch/ (accessed November, 2010).

McGonigal, Jane. Reality is Broken: Why Games make Us Better and how they can Change the World. London: Jonathan Cape, 2011.

mia1984. (2010) "Indonesians on the Social Network." Available at http://mia1984.wordpress.com/2010/10/29/indonesians-on-the-social-network/ (accessed April, 2011).

Montola, Markus, Jaakko Stenros, and Annika Waern. Pervasive Games: Theory and Design. Burlington: Morgan Kaufman, 2009.

Montola, Markus. "Games and Pervasive Games." In: Montola, Markus, Jaakko Stenros, and Annika Waern (eds.). Pervasive Games: Theory and Design. Burlington: Morgan Kaufman, 2009. pp, 7-24.

de Paoli, Stefano, and Aphra Kerr. "The Cheating Assemblage in MMORPGs: Towards a Sociotechnical Description of Cheating". Breaking New Grounds: Innovation in Games, Play, Practice, and Theory - DiGRA 2009 Conference. Brunel University, West London.

Pargman, Daniel, and Peter Jakobsson. "Do You Believe in Magic? Computer Games in Everyday Life." Eureopean Journal of Cultural Studies. Vol. 11, No..2 (2008): pp. 225-44.

Robertson, Margaret. (2010) "Can't play, won't play." Hide\&Seek. Available at http://www.hideandseek.net/cant-play-wont-play/ (accessed March, 2011).

Salen, Katie, and Eric Zimmerman. Rules of Play, Game Design Fundamentals. Camebridge: The MIT Press, 2004.

Stenros, Jaakko, Markus Montola, and Frans Mäyrä. "Pervasive Games in Media Culture." In: Montola, Markus, Jaakko Stenros, and Annika Waern (eds.). Pervasive Games: Theory and Design. Burlington: Morgan Kaufman, 2009. pp. 257-276.

Team Foursquare. (2010) "On foursquare, cheating, and claiming mayorships from your couch..." Available at http://blog.foursquare.com/2010/04/07/ 503822143/ (accessed February, 2011).

Tondorf, Woody. (2010) Foursquare Cops. HubSpot Blog. Available at http://blog.hubspot.com/foursquare-cops/tabid/76228/Default.aspx (accessed April, 2011). 